\title{
TYPUS DEGENERATIVUS AMSTELODAMENSIS
}

\author{
BY \\ BERNARD SCHLESINGER, BARBARA CLAYTON, MARTIN BODIAN \\ and K. VERNON JONES* \\ From The Hospital for Sick Children, Great Ormond Street, London
}

(RECEIVED FOR PUBLICATION JANUARY 10, 1963)

In 1933 Cornelia De Lange first described two infant girls in Amsterdam with mental deficiency, a curious facies and various abnormalities. Not venturing to give the syndrome her own name she called it Typus Degenerativus Amstelodamensis, using the old name of the town where the children lived. Five years later she reported a third case and also gave details of an autopsy carried out on the first child who had died at the age of $5 \frac{3}{4}$ years from cerebral sinus thrombosis and extensive subarachnoid haemorrhage (De Lange, 1938). The brain was microcephalic with a diminished number of convolutions; there was an abnormal attachment of the mesentery, and microscopic examination revealed absence of colloid in the thyroid.

Some 24 further examples of the disorder have been recorded in several European countries, but beyond confirming the same clinical features with certain variations and mentioning other congenital abnormalities the accounts contributed nothing more to the pathogenesis of the disease (Vedder, 1935; Pincherle, 1939; Marie, Seringe, Cousin and Renaud, 1946; Clog, Blanchet and Travade, 1947; Marie and Seringe, 1948; Ullrich, 1951; Keizer, 1952; Arnaud-Battandier and Gillot, 1953; Borghi, Giusti and Bigozzi, 1954; Bardier and Degoy, 1956; Zunin, 1957; Richter, 1961). Zweymüller (1957) was the first to investigate the syndrome from an endocrine angle and using $\mathrm{I}^{131}$ was able to demonstrate that radioactive iodine uptake was very deficient and rose appreciably after injecting thyroid stimulating hormone. He suggested that the mental retardation might well be the result of the secondary hypothyroid state.

Our interest in the condition was stimulated by an unpublished paper given by Dr. de Bruijne in London in 1961. As far as we are aware it has not so far been identified in England, and so the interest evoked by an affected child who came under the care of one of us (B.S.) led to the rapid recognition

\footnotetext{
* Now serving with B.A.O.R.
}

of five further cases attending the hospital, which had previously not been classified. Recent advances in investigation of endocrine function, which we have been able to employ in these children, and the opportunity that autopsy provided of histological examination of the endocrine glands in two cases are the main objects of this publication. The following description of the clinical picture covers all six children and a detailed account of each individual case seems unnecessary. Nevertheless, in order to relate certain clinical variations with the endocrine studies and autopsy findings, the initials are given so that they might be identified. They are G.McD., L.Bu., D.H., C.W., L.Be. and S.M.

\section{Clinical Picture}

Children with this disorder all follow the same pattern, though there may be slight modifications. The picture in our six cases corresponded very closely to that which has appeared in the literature. We have been able to study the condition in two boys and four girls, their ages ranging from 9 months to 6 years.

History. Their antenatal history revealed nothing abnormal, and the mothers were healthy throughout pregnancy, except for slight oedema of the feet in one and an attack of influenza at the sixth month in another. Caesarean section was carried out in one for an unstable lie; the rest were delivered normally. All the infants were born at full term except one, who was one week premature. Nevertheless, the birth weights were all below $6 \mathrm{lb}$. $\left(2,721\right.$ g.), namely 5 lb. $15 \frac{1}{2}$ oz. (2,706 g.), $5 \mathrm{lb} .6 \mathrm{oz}$. (2,437 g.), 4 lb. 7 oz. (2,012 g.), 4 lb. 7 oz. (2,012 g.), $5 \mathrm{lb} .11 \mathrm{oz} .(2,578 \mathrm{~g}$.) and $5 \mathrm{lb} .4 \mathrm{oz}$. $(2,380 \mathrm{~g}$.$) . A$ poor condition at birth was reported in four of the infants, cyanotic attacks and failure to cry or suck being observed, and one child was stated to be in 'coma' for three days. These events required oxygen and two had to be nursed in an incubator for several weeks. Difficulty in feeding, sometimes 

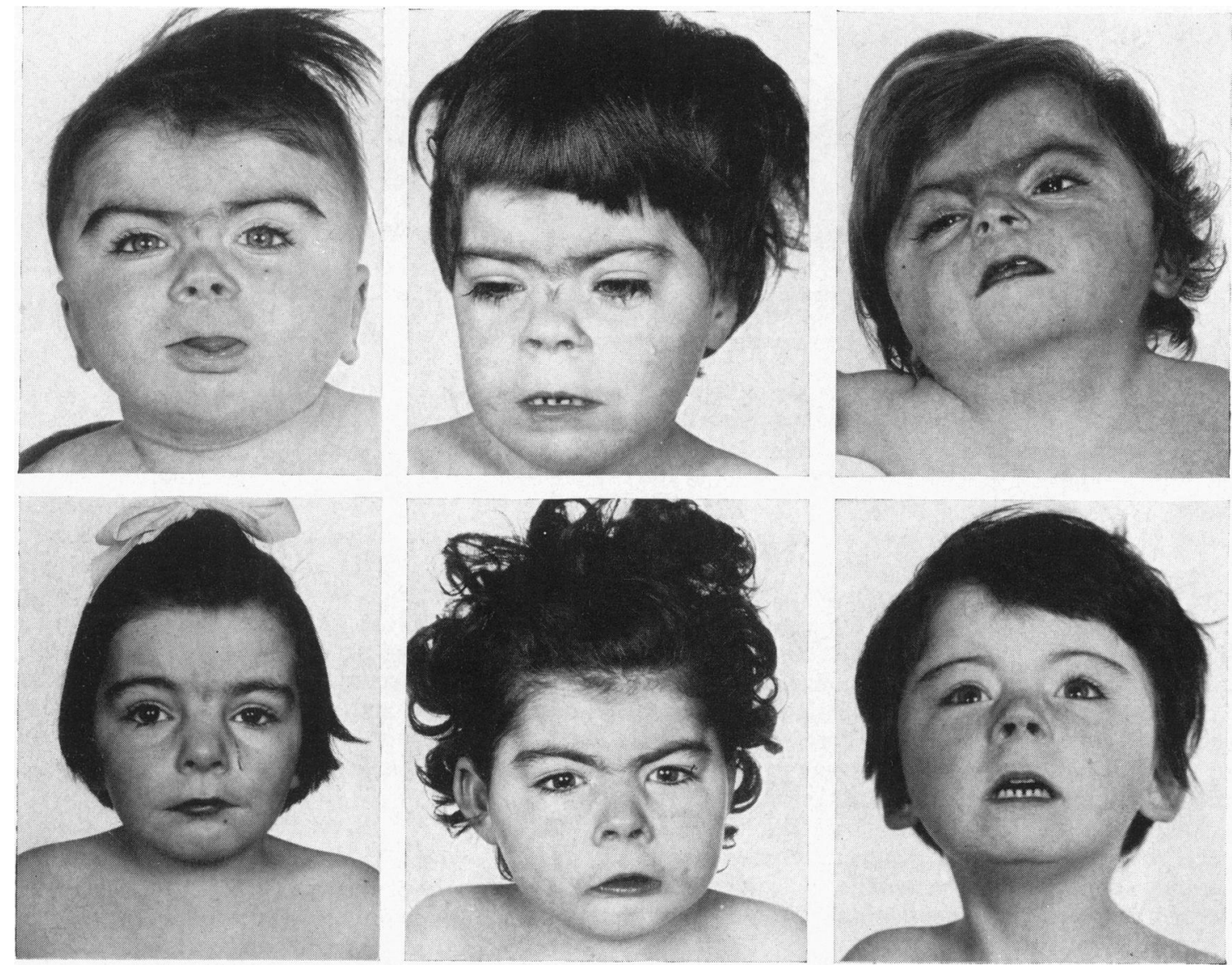

FIG. 1.-Characteristic facies of the six children, from left to right: G.McD.; L.Be.; D.H.; C.W.; L.Bu.; and S.M.

with vomiting, was experienced in all the infants, resulting in a slow gain in weight. Recurrent episodes of respiratory infection were also noted.

There was nothing in the family history suggesting a hereditary disorder.* The parents were healthy and not related. The mean maternal age for the group at the time of birth of the cases was 30, and paternal age 34, against means for England and Wales of 27.9 and 30.2 respectively. The order in the family appeared to play no part. Two of the infants were first pregnancies, two second and one the result of a fourth conception. A single miscarriage was reported in three of the families, but bore no special relation in time to the abnormal infants we are considering. Older or younger siblings, present in each case, were all normal and healthy.

\footnotetext{
* A possible hereditary factor has been noted in a family described by Borghi et al. (1954).
}

Clinical Examination. Physical examination revealed a picture so identical in this small series that a single description will cover all six children. The facies was quite characteristic from birth onwards, without any of the occasional doubts that can arise in infant mongols. The most striking features were bushy eyebrows, meeting in the midline, hair growing well down the forehead, long eyelashes and a narrow palpebral fissure. The nose had a flat bridge, was short and upturned with forward tilting nostrils. The upper lip was thin but wide and situated at an abnormal distance from the nasal septum, giving the mouth a carplike appearance (Fig. 1). The teeth, when present, were small and widely spaced. The head was small and brachycephalic with a flattened occiput, the ears were low and deeply set, the neck was short and webbed (Fig. 2). Occasionally nystagmus was present. It has been said that children with this disorder 
have the appearance of a ventriloquist's dummy, but we are not altogether impressed with this likeness. There was a normal proportion in the build of the body and limbs, but height and weight were well below the third percentile and continued so as age advanced in all our cases. It was striking how dark and coarse the hair grew and that often parts of the body were also covered in the same way. The skin was generally rough and dry.

The hands were characteristic, with a flat spadelike appearance and short tapering fingers, the fifth especially so and curving inwards. A single deep transverse crease was seen over the palms, although in one case (C.W.) this was only on one side. This child also had a normal palmar triradius, whereas in all the others this was high, giving an ATD angle in the region of $80 \mathrm{deg}$., considerably wider than the average normal. Single finger creases were also present, although sometimes this varied. The thumbs appeared to originate from a proximal position, producing a poor thenar eminence, rather like a lobster's claw (Fig. 3). Limitation of full extension of the elbows and of supination of the forearms was another feature.

In the lower limbs impaired joint movement was only noticed in one case, where full extension of the hips and knees was impossible. The feet appeared small, chiefly owing to the short toes, and syndactyly, usually of the second and third toes, was present in half the cases (Fig. 4).

It is of some significance, to which we will refer later, that the genitalia in the boys were immature, and the testes hypoplastic.

Progress of all the children remains slow, psychomotor development is delayed and mental impairment seems to be permanent. This varies in degree; for instance, there is little response in one girl (L.Be.) of $4 \frac{1}{2}$ years who does not recognize her parents, whereas in another (C.W.) a girl of 6 years, already mentioned as having less marked physical abnormalities, the I.Q. is 65 , and being friendly and interested, she is able to benefit from an educationally subnormal school. Between these two extremes there are gradations in mental retardation, but speech is always late in developing and some of them continue to express themselves with a hoarse cry.

Radiology. Radiological examination revealed a small vault to the skull with a normal pituitary fossa. The bone age was much retarded in all but one girl (C.W.) who, in other ways we have already indicated, seemed less severely affected. There was also shortening and sometimes deformity of the first metacarpal bone and, in certain instances,

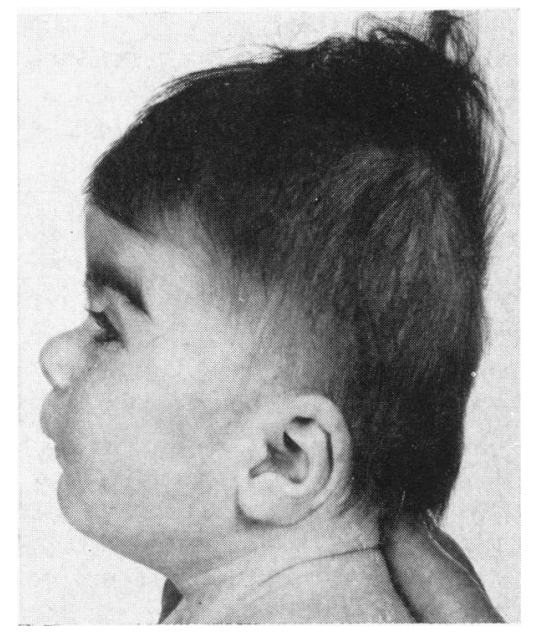

FIG. 2.--Showing the flattened occiput, short neck and low set ears.

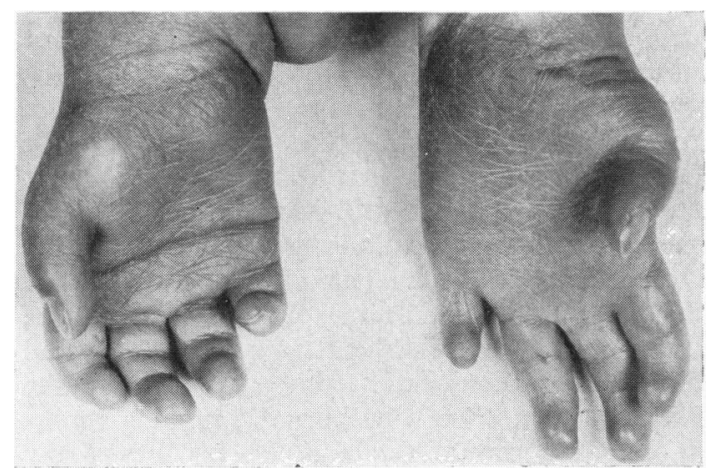

Fig. 3.-Note the curious hands with short tapering fingers, single transverse crease on the palms and digits and the 'lobster claw' thumb.

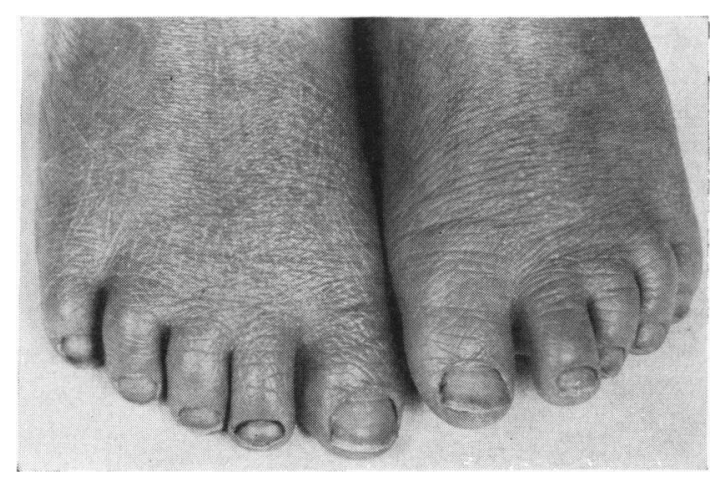

FIG. 4.-The toes are short and syndactyly of the second and third is present. 
an abnormal shape of the upper end of the radius. The vertebrae throughout were normal and so the short webbed neck has no skeletal basis.

Other Abnormalities. With so many abnormalities, other developmental defects can be expected. Congenital malformation of the heart has been described in several of the previously published cases, and in five of our six children a cardiac murmur suggested this. One (D.H.) came to autopsy, where a grossly abnormal venous drainage was found. Hypospadias, spina bifida, cleft palate (noted in two of our cases), pyloric stenosis and hiatus hernia have all been recorded. More serious, however, are certain gut abnormalities. Our experience seems to have been different from that of others in this respect, as these have not been previously mentioned in the published reports, except in Cornelia De Lange's first case, where an odd attachment of the mesentery was found.

Malrotation of the gut was present in one of our children (D.H.), who died of a very severe bronchiolitis. There had been no abdominal symptoms during life, but in another child (L.Bu.) the same abnormality caused obstruction at the duodenum through bands and adhesions, which had to be relieved by operation. In a third child (G.McD.) there was an unsuspected duplication of the transverse colon, the duplication ending blindly. Here an ulcer formed, which perforated and the child quickly died from peritonitis. Such events in three out of six children are certainly significant and indicate that congenital abnormalities of the alimentary tract should be borne in mind. Persistent vomiting should therefore always arouse the suspicions of anyone looking after a child with this syndrome. It would be safest to carry out barium visualization of the intestines in every case, because, as we have seen, the condition may be symptomless and pass undetected, until ultimately there may be a catastrophic termination.

In regard to special weaknesses, these children seem to have little resistance when they are young and withstand infections very badly. Repeated alarming attacks of pneumonia or bronchitis may occur which react slowly to antibiotics, and in one of our cases the bronchiolitis proved fatal. There is no lack of $\gamma$ globulin and, as we shall demonstrate later, failure of part of the adrenal cortex may well play a part, although this is not reflected in any electrolyte disturbance at the time.

\section{Material and Methods}

Chromosomes. Chromosome studies were carried out on two patients by Professor Polani. G.McD. had a modal number of 46 chromosomes with an $X Y$ sex chromosome complement and no abnormality of the autosomes. L.Bu. had a modal number of $\mathbf{4 6}$ chromosomes with an XX sex chromosome complement. There was a possible variation of the satellites of the chromosomes in groups 13-15 (Human Chromosomes Study Group, 1960), the meaning of which is obscure. In all six cases the sex chromatin pattern corresponded to that of the apparent sex.

Endocrine Studies. These were carried out in four of the six cases. Anterior pituitary function was assessed by the following tests which included the responses of the target organs, viz. the adrenal cortex and thyroid gland.

1. Insulin tolerance and ability to respond to hypoglycaemia (Daniel, 1941): Full-strength and halfstrength doses $=0 \cdot 25$ and $0 \cdot 125$ units soluble insulin $/ \mathrm{kg}$. body weight, respectively. The overall effect of insulin is to lower blood sugar and that of corticoids and growth hormone to raise it. Normally, blood sugar is maintained as a result of a complex balance between a number of hormones, and if an insulin-antagonizing hormone is absent, sensitivity to insulin is exaggerated (De Bodo and Altszuler, 1958). The test has proved of value in the diagnosis of hypopituitarism and/or poor adrenocortical function (Fraser, Albright and Smith, 1941).

2. Serum protein-bound iodine on venous blood by the method of Grossmann and Grossmann (1955).

3. Thyroid uptake of ${ }^{132}$ iodine: uptake over the neck was measured at varying intervals after the oral administration of $5 \mathrm{mc} \mathrm{I}^{132}$. In G.McD., the measurements were repeated after three days' stimulation with thyrotropic hormone (5 units daily, i.m., Armour Laboratories Ltd.).

4. Adrenocorticotropic hormone (A.C.T.H.) test (Clayton, Edwards and Renwick, 1962). This measures the ability of the adrenal cortex to respond to A.C.T.H.

5. Metopirone test: 17-ketosteroids (second method of Prout and Snaith, 1958) and total 17-hydroxycorticoids (Appleby, Gibson, Norymberski and Stubbs, 1955) were estimated in each of five consecutive 24-hour collections of urine. Metopirone (11ß-hydroxylation inhibitor, Ciba Laboratories Ltd.) was administered orally every four hours during the third 24 hours in a dosage of $11 \mathrm{mg} . / \mathrm{kg}$. body weight. This test depends upon the fact that cortisol secretion is reduced as a result of impaired $11 \beta$-hydroxylation by 'metopirone' (Liddle, Island, Lance and Harris, 1958). The normal inhibitory effect of cortisol on the anterior pituitary gland is removed and increased secretion of A.C.T.H. results, intensifying the production of 11-desoxycorticosteroids such as compound $\mathrm{S}$. These metabolites are estimated as 17hydroxycorticoids in the urine. This provides a sensitive means of testing the integrity of the pituitaryadrenal axis, provided some adrenocortical response to exogenous A.C.T.H. is possible.

6. Plasma electrolytes, blood urea, blood sugar and serum cholesterol on heel or finger-prick blood by micromethods described by Wilkinson (1960). 
TABLE 1

TESTS OF ENDOCRINE FUNCTION

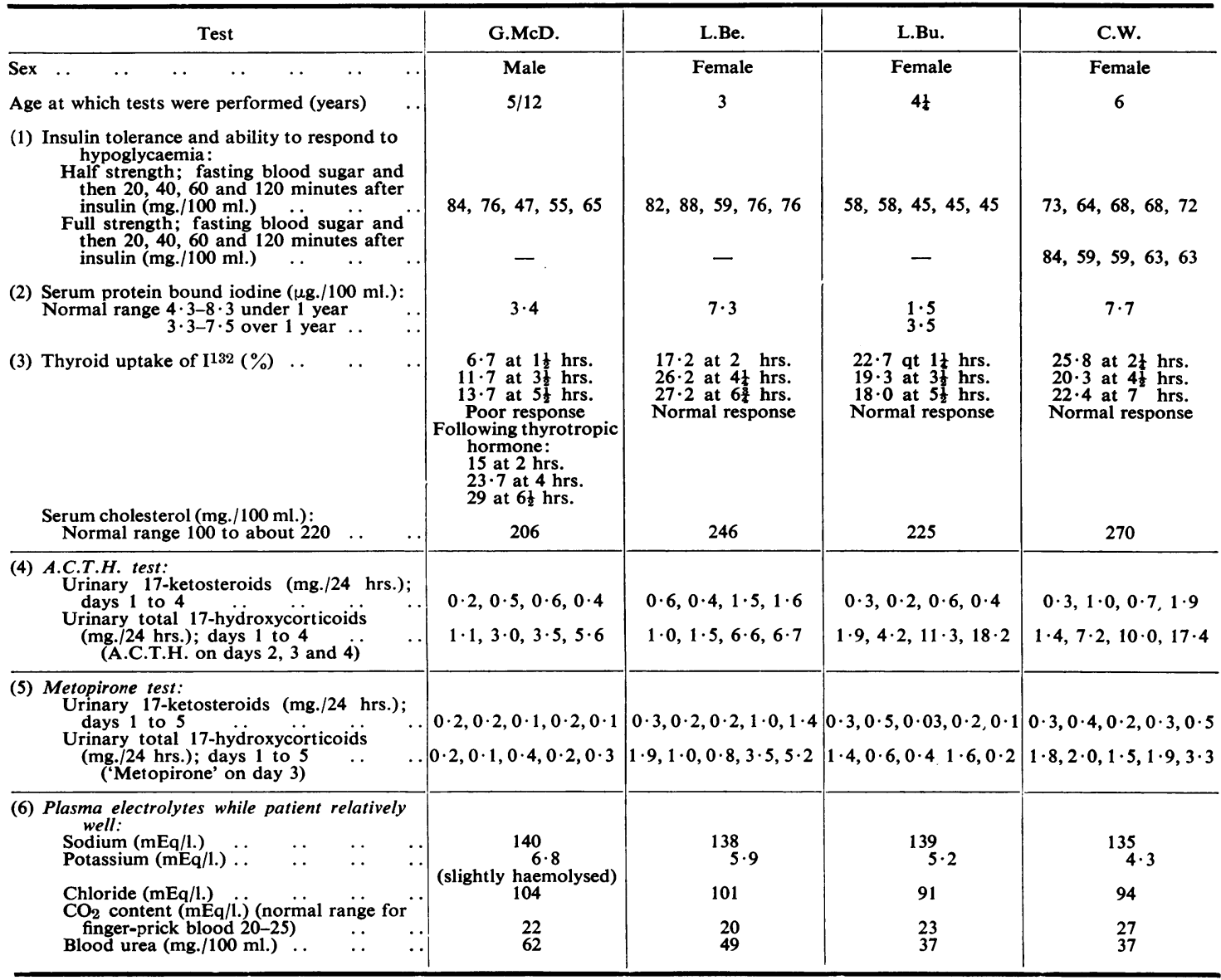

\section{Results}

The results of the investigations are given in the Table where the serum cholesterol levels have been included among the other tests of thyroid function.

Preliminary testing with insulin in G.McD., L.Be. and L.Bu. showed abnormal sensitivity; in addition, L.Bu. had a low fasting blood sugar and produced no compensating reaction to hypoglycaemia. Though C.W. had a normal tolerance for insulin, her ability to respond to hypoglycaemia resulting from a full dose of insulin was poor. Since these findings were compatible with a diagnosis of hypopituitary and/or poor adrenocortical activity (Fraser et al., 1941), further tests of endocrine function were performed. The four patients investigated exhibited varying abnormalities.
No evidence of thyroid dysfunction was observed in two of the patients (L.Be. and C.W.). In contrast, G.McD. had a low protein-bound iodine and the uptake of $\mathrm{I}^{132}$ by his thyroid was poor, but improved in response to thyrotropic hormone as described by Zweymüller (1957). Though the protein-bound iodine was low in L.Bu., her thyroid uptake of $\mathbf{I}^{132}$ was normal and it is possible that she had a deficiency of thyroid-binding globulin (Tanaka and Starr, 1959).

The normal range for serum cholesterol has wide limits, particularly in children, and in none of the four patients examined was the level so high that it was possible to say it was definitely abnormal.

In a normal child, the urinary output of 17hydroxycorticoids in response to a standard A.C.T.H. 
test should reach at least $20 \mathrm{mg}$./24 hours (Clayton et al., 1962). By this criterion, all the patients exhibited some degree of adrenocortical insufficiency, mild in L.Bu. and C.W., but very severe in G.McD. and L.Be. There was a failure to respond to 'metopirone' in G.McD., L.Bu. and C.W., indicating that their pituitary glands had failed to secrete A.C.T.H., and that adrenocortical hypofunction was dependent on a pituitary lesion. In L.Be. the poor response to A.C.T.H. was accompanied by a definite response to 'metopirone', suggesting that there might have been a primary adrenal insufficiency rather than a primary pituitary lesion.

No disturbance of plasma sodium or potassium was observed. This suggested that the zona glomerulosa in the adrenal of these children was intact, since this zone secretes aldosterone which is largely responsible for electrolyte and water regulation. Unlike the zona fasciculata which produces cortisol, the zona glomerulosa is controlled only to a small extent by the anterior pituitary gland and does not undergo complete atrophy following experimental hypophysectomy (Sayers, 1962).

The blood urea was abnormally raised in G.McD. and L.Be.; the reason for this is not known.

\section{Autopsy Reports}

Post-mortem findings are recorded in two children, aged 2 years and 3 months and $8 \frac{1}{2}$ months respectively (D.H. and G.McD.).

The skull in both cases was brachycephalic and also plagiocephalic in one. The sella turcica was of abnormal shape with shallow anterior and overhanging large posterior clinoid processes. The size of the fronto-occipital circumference was below the third percentile in both children and the brain was microcephalic, respectively 300 and $200 \mathrm{~g}$. below the expected weight. Cerebral convolutions were unduly narrow and intergyral sulci wide. Microscopically there was some cortical atrophy in both cases, with diffuse gliosis in one and some degeneration of myelin in the other.

The pituitary gland histology was similar in both instances. There were ample eosinophilic cells. The main pathology was the absence of basophilic cells, which were replaced by cells of amphoteric appearance containing rather scanty P.A.S. positive granules. Normal basophilic cells are thought to be responsible for the production of thyroid stimulating hormone, A.C.T.H. and gonadotrophin, and the changes suggest a deficiency in the production of these hormones. Accordingly in both cases there were abnormalities of the thyroid gland (Figs. 5, 7 and 8). Colloid formation was poor, either absent or weakly staining, vacuolated and of a curious fibrillary appearance. The lining epithelial cells were usually low cuboidal.

The testes were small but showed no definite histological change. They were incompletely descended in both cases.

The islets of Langerhans were normal.

The adrenal glands were small and thin in both cases, with ample lipoid in all zones of the cortex in one, but depletion of lipoid from the zona fasciculata in the other (Figs. 6 and 9).

Other lesions in D.H. included anomalous systemic venous drainage into a persistent coronary sinus of the right atrium with consequent centrilobular hepatic necrosis, acute bronchitis and bronchiolitis, non-rotation of large and small intestines and cortical nephrocalcinosis. G.McD. succumbed to acute peritonitis following perforation by impacted faeces of the blind end of a colonic duplication.

In summary, there was microcephaly and cortical cerebral atrophy in both cases, with histological evidence of multiple endocrine-granular pathology, including deficiency of the tropic hormoneproducing cells of the anterior pituitary gland, hypoplasia of the thyroid gland, adrenal cortex and probably of testes as well. Other malformations included abnormal systemic venous drainage, nonrotation of the gut and duplication of the colon.

Both cases succumbed to acute infections, respiratory in one and peritonitis in the other.

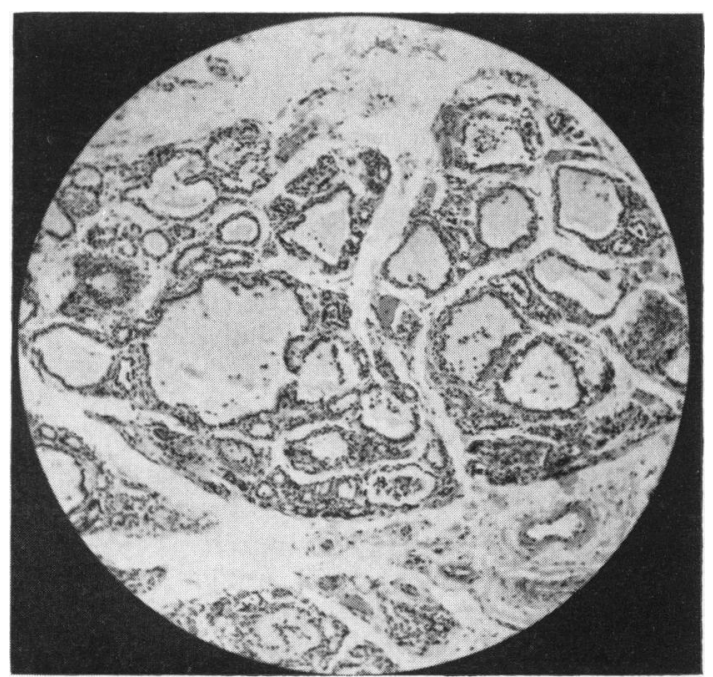

Fig. 5.-D.H. P.M.3/62. Photomicrograph of thyroid gland. $(x$ 60.) Acini lined by cuboidal epithelium. Poorly staining vacuolated colloid. 


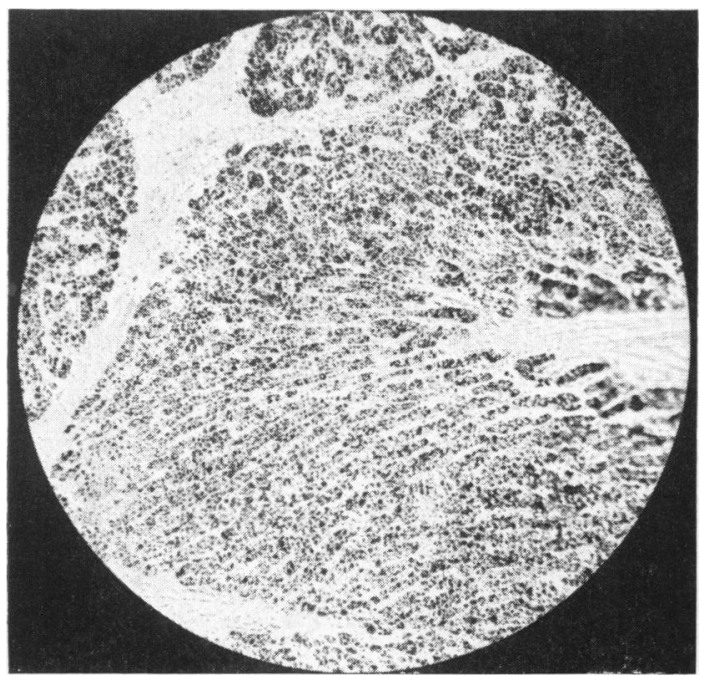

FIG. 6.-D.H. P.M.3/62. Photomicrograph of adrenal gland. ( $x$ 60.) Thin cortex with ample lipid in all zones.

\section{Treatment}

Obviously no form of treatment is likely to influence the ultimate course of the disease. If thyroid deficiency can be proved, thyroxine is

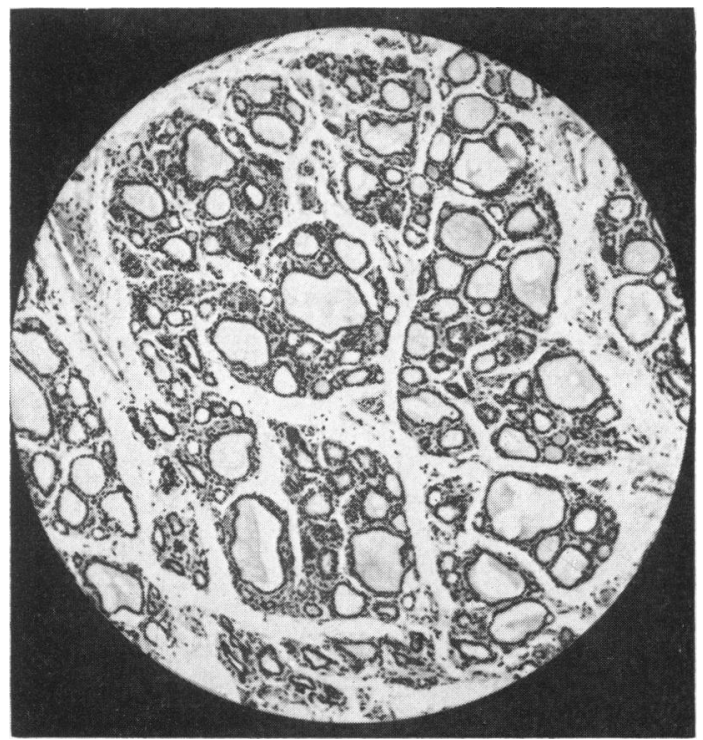

Fig. 7.--G.McD. P.M.40/62. Photomicrograph of thyroid gland. ( $\times 60$.) Moderately dilated acini lined by low cuboidal epithelium and filled with poorly staining colloid.

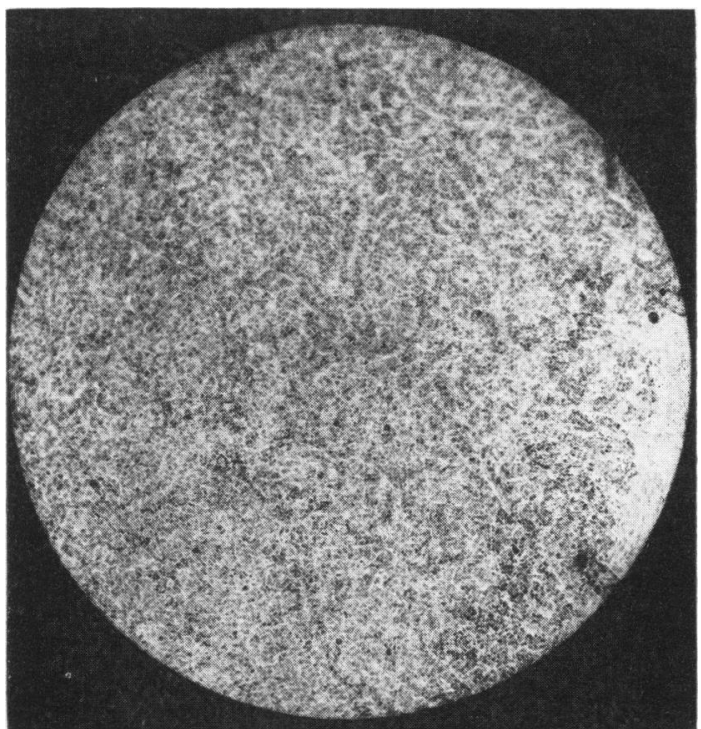

FIG. 9.-G.McD. P.M.40/62. Photomicrograph of frozen section of an adrenal stained for fat. $(\times 60)$ The zona glomerulosa contains ample lipid; the zona fasciculata has discharged most of its fat.

indicated, but we have not seen any substantial improvement in mentality in the few patients to whom we have given it. It also seems reasonable to give cortisone or one of its derivatives to cover an

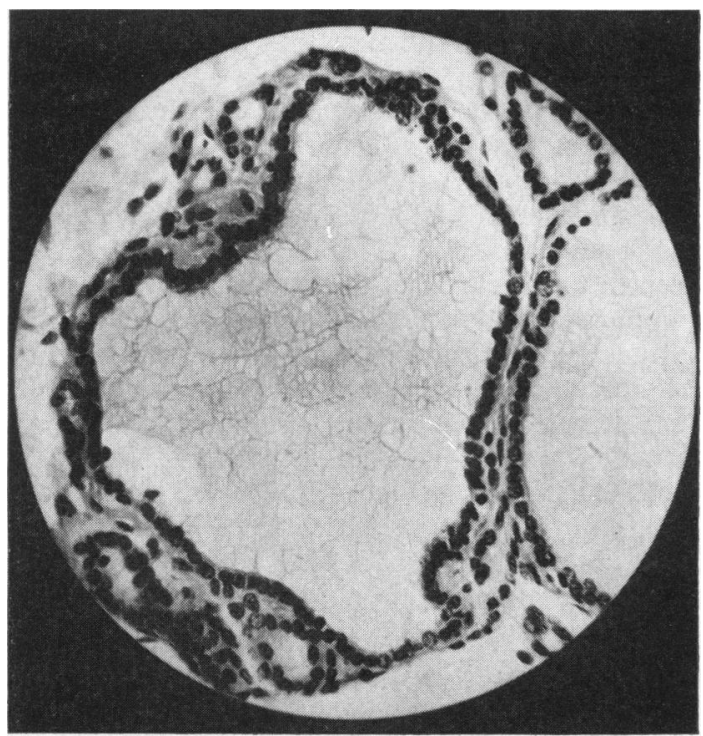

Fig. 8-G.McD. P.M.40/62. Photomicrograph of thyroid gland. ( $\times$ 240.) The cuboidal epithelium is shown as well as the curious fibrillary pseudo-vacuolated appearance of the colloid. 
infection or operation, since these children are incapable of producing their own effectively in times of stress. At the same time an appropriate antibiotic should be freely prescribed. When a human growth hormone becomes generally available, this might also be used. The anabolic drugs we have tried have failed in this respect. There is, unfortunately, no means of improving the mental retardation which is the most distressing feature.

\section{Discussion}

The clinical features of typus degenerativus amstelodamensis are distinctive. Attention is drawn to the relative frequency of abnormalities of the gastro-intestinal tract. These may be asymptomatic and serious complications can arise, which might only have been anticipated by deliberate radiological investigation in all cases.

Tests of endocrine function in four children showed evidence of hypopituitarism which was least marked in the 6-year-old girl, C.W., and it was in her case that some modification of the clinical picture was found. Histological study of the pituitary gland in two instances supported these observations.

Thyroid deficiency was not always present, but in one child laboratory tests gave clear evidence of this, and after death further support was obtained from histological changes in the gland. A similar degenerative appearance was obvious in another fatal case, but here no endocrine investigations had been carried out during life. In a third child some defect in thyroid function was suspected, but this was possibly a deficiency of thyroid-binding globulin. In no instance did the thyroid defect amount to that encountered in cretinism.

A varying degree of adrenocortical insufficiency was discovered in the four children investigated. Their reactions to A.C.T.H. and 'metopirone' tests seemed to indicate that this was secondary to hypopituitarism in three, but in one the results were more in favour of a primary defect of the adrenal gland. Microscopical examination of the suprarenal cortex in the two autopsies was consistent with partial adrenal failure. The glands were small, and in one there was depletion of lipid in the zona fasciculata, pointing to poor secretion of glucocorticoids. The absence of any clinical disturbance in the electrolyte levels and the autopsy finding of a normal zona glomerulosa with ample lipid are quite compatible with a hypopituitary state for the reasons already given.

From the present study it is obvious that the endocrine system is affected to a varying extent in different instances, but there is no evidence that this syndrome is primarily an endocrine disorder. The mental deficiency may possibly be the secondary result of a prolonged thyroid defect. Susceptibility to infection may also be a reflection of a poor adrenal reaction, and growth failure could be due to lack of pituitary growth hormone. Small genitalia are known to be associated with hypopituitarism.

The cause of the peculiar aspect remains unexplained. It has not been seen in any other disease and for the moment it must be accepted as one of the many other congenital abnormalities present. We conclude that endocrine gland deficiency in this syndrome comes under the same category, although the result of the various defects may certainly influence the development and course of the disorder. No known chromosome abnormality could be found and no hereditary factor was discovered. The aetiology of de Lange's syndrome, which for simplicity we think is a more appropriate term, will have to await further elucidation.

\section{Summary}

Six cases of a syndrome first reported by Dr. Cornelia de Lange are described, together with their possible complications. Defective function of the anterior part of the pituitary body has been demonstrated, with secondary effects on the other endocrine glands. The disorder appears to be the result of multiple congenital abnormalities which have no demonstrable hereditary basis and are not associated with a known anomalous chromosome pattern.

We are grateful to our colleagues at The Hospital for Sick Children, Great Ormond Street, for allowing us to study some of their cases. We also wish to thank Dr. Gimlette of St. Thomas's Hospital for his help in measuring the thyroid uptake of $\mathbf{I}^{132}$ and Professor Polani of Guy's Hospital for investigating the chromosome pattern. We are indebted to Mr. Derek Martin for the illustrations.

REFERENCES
Appleby, J. I, Gibson, G., Norymberski, J, K and Stubbs, R, D. (1955). Indirect analysis of corticosteroids. I. The deter(1955). Indirect analysis of corticosteroids. I. The det

mination of 17-hydroxycorticoids. Biochem. J., 60, 453 .
Arnaud-Battandier, R. and Gillot, F. (1953). Un nouveau cas de typus amstelodamensis. Pédiatrie, 8, 100.

Bardier, A. and Degoy, A. (1956). Un cas de typus Amstelodamensis. Arch. franc. Pédiat., 13, 920.

Borghi, A., Giusti, G. and Bigozzi, U. (1954). Nanismo degenerativo tipo di Amsterdam. Acta Genet. med. (Roma), 3, 365.

Clayton, B. E., Edwards, R. W. H. and Renwick, A. G. C. (1962). Adrenal function in children. Arch. Dis. Childh., 38, 49.

Clog, L. W., Blanchet and Travade (1947). Un nouveau cas de typus amstelodamensis. Coexistence d'une hypertrophic musculaire géneralisée. Arch. frans. Pédiat., 4, 100.

Daniel, W. A. (1941). A study of insulin tolerance and glucose tolerance tests on normal infants. J. Pediat., 19, 789.

De Bodo, C. and Altszuler, N. (1958). Insulin hypersensitivity and physiological insulin antagonists. Physiol. Rev., 38, 389.

De Lange, C. (1933). Sur un type nouveau de dégéneration (typus Amstelodamensis). Arch. Méd. Enf., 36, 713 .

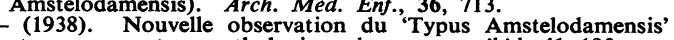
et examen anatomopathologique de ce type. ibid., 41, 193.

Fraser, R., Albright, F. and Smith, P. H. (1941). The value of the glucose tolerance test, the insulin tolerance test and the glucose insulin tolerance test in the diagnosis of endocrinologic disorders of glucose metabolism. J. clin. Endocr., 1, 297. 
Grossmann, A. and Grossmann, G. F. (1955). Protein-bound iodine by alkaline incineration and a method for producing a stable cerate color. ibid., 15, 354 .

Human Chromosomes Study Group (1960). A proposed nomenclature of mitotic human chromosomes. Cerebr. Palsy Bull., Suppl. to 2, No. 3 .

Keizer, D. P. R. (1952). Typus degenerativus Amstelodamensis (Cornelia de Lange). Helv. paediat. Acta, 7, 508.

Liddle, G. W., Island, D., Lance, E. M. and Harris, A. P. (1958). Alterations of adrenal steroid patterns in man resulting from treatment with a chemical inhibitor of $11 \beta$-hydroxylation. J. clin. Endocr., 18, 906.

Marie, J. and Seringe, P. (1948). Le Nanismes: Nanismes microcéphales. In Lemierre, A. et al. Traité de Medec., 13, 1048. Libraires de l'Académie de Médicine, Paris.

, - Cousin, M. and Renaud, D. (1946). Typus Amstelodamensis. Nourrisson, 34, 1.

Pincherle, B. (1939). Première observation du Typus Amstelodamensis (de Lange) en Italie. Arch. Méd. Enf., 42, 443.
Prout, M. and Snaith, A. H. (1958), Urinary excretion of 17-ketosteroids in children. Arch. Dis. Childh., 33, 301.

Richter, H. (1961). Drei neue Beobachtungen des Cornelia-deLange-Syndroms (Typus degenerativus Amstelodamensis). Arch. Kinderheilk., 164, 249.

Sayers, G. (1962). The Human Adrenal Cortex, ed. A. R. Currie, T. Symington and J. K. Grant, p. 181. Livingstone, Edinburgh and London.

Tanaka, S. and Starr, P. (1959). A euthyroid man without thyroxinebinding globulin. J. clin. Endocr., 19, 485.

Ullrich, O. (1951). Typus Amstelodamensis Ergebn. inn. Med. Kinderheilk., II, 454.

Vedder, R. (1935). Een 'Typus degenerativus amstelodamensis' (de Lange). Ned. T. Geneesk, 79, 993

Wilkinson, R. H. (1960). Chemical Micro-methods in Clinical Medicine. Charles C. Thomas, Springfield, Illinois.

Zunin, C. (1957). Typus degenerativus amstelodamensis. Minerva pediat., 9, 725 .

Zweymüller, E. (1957). Neue Beobachtungen an einem Typus degenerativus Amstelodamensis (Cornelia de Lange). Neue öst. Z. Kinderheilk., 2, 40. 